\title{
Modelling and Analysis of Traffic Light Control Systems Using Timed Coloured Petri nets
}

\author{
Yi-Sheng Huang ${ }^{1}$ and Ta-Hsiang Chung ${ }^{2}$ \\ ${ }^{1}$ Department of Electrical and Electronic, National Defense University, \\ Taoyuan 335, Taiwan, R.O.C. \\ 2 Air Force Institute of Technology, Taiwan, R.O.C.
}

\begin{abstract}
An urban traffic network of signalized intersections can be suitably modeled as a discrete event system, in which the traffic light alternations are described by means of Timed Coloured Petri nets (TCPN). In this chapter, a module of basic traffic TCPN model with a signal timing plan for a day is successfully constructed. The traffic operations are ruled by the control logic of TCPN and an analysis method of place invariant is verified. Based on the basic TCPN model, some of complicated traffic signal models will be easily obtained. Moreover, a real-world supervisor of the urban traffic light system is implemented by the new methodology. Finally, an urban traffic light control systems with five intersections has been realized. Additionally, the performance of the supervisor of the urban traffic light system can be confirmed by the simulation results.
\end{abstract}

Keywords: Petri nets, traffic control, intelligent transportation systems.

\section{Introduction}

With the growing number of vehicles, the traffic congestion and transportation delay on urban arterials are increasingly worldwide. Therefore it is a practical importance to develop, verify and validate simple, yet powerful models that help in design and improve the safety and efficiency of transportation. It is a significant issue to control traffic lights in roadvehicle systems. The main reasons to the traffic signals are used to manage conflicting requirements for the use of road space - often at road junctions - by allocating right of way to different sets of mutually compatible traffic movements during distinct time intervals.

The traffic light control systems regulate, warn and guide transportation for the purpose of improving the safety and efficiency of pedestrians and vehicles. There are a lot of literatures to develop various strategies [1-10] and they are classified into two categories [11]: 1) Fixedtime strategies and 2) Traffic-response strategies. An urban traffic control in most of industrialized countries has been used fixed-time strategies to nowadays. In addition, the topic of traffic signal control can be separated into two categories [12]: 
1) determine what signal-indication sequence in following order optimizes the system performance and 2) ascertaining how to implement the signal control logic. This chapter centralizes on the second category with a traffic signal timing plan that is a predetermined time.

Petri nets (PN) have been proven to be a powerful modeling tool for various kinds of discrete event systems [13-14], and its formalism provides a clear means for presenting simulation and control logic. Hence, the PN is applied in traffic control. In fact, traffic control has been accomplished by using Petri nets [15-18]. In [19] chooses Deterministic and Stochastic Petri Nets (DSPNs) as the modeling tools. The behavior of the pre-timed twophase signal is depicted. The green periods, and the cycle lengths are predetermined and of fixed duration. The approach via programmable logic control (PLC) and Petri nets synthesis is proposed in [20]. Its traffic lights contain three-color lights, and each lane has a series light whose signal will be changed by the regular time intervals. And the model of traffic light is used by Petri nets. In [21] a signal timing plan is proposed by timed Petri net (TPN). The streams allowed us to proceed with the eight-phase of the signal timing plan. Recently, an urban traffic light controller using statecharts is proposed [22] which includes eight-phase, six-phase and two-phase.

As mentioned above, the models of traffic light systems only have one set of phase duration. Obviously, the timing plan of traffic light to be a leading role in urban traffic light systems. And it can determine the optimal splits and the optimal cycle time. It hints that there are many sets of phase duration varied with traffic flow in a day. As a result, the authors propose a new modeling methodology to tackle this difficult problem in this chapter. To sum up, a traffic light control system with multi-set of phase duration has been designed based on TCPN.

This chapter is arranged as follows. Section 2 briefly introduces basic definitions of TCPN that are related to this chapter. Section 3 depicts how to model the traffic lights by using TCPN. Additionally, the analysis of the TCPN models is presented in section 4. Finally, some conclusions are given in section 5 .

\section{The basic definitions of TCPN}

We first introduce the new methodology which is based on a global clock. The global clock values represent the system model time where they may either be discrete or continuous. More precisely, each token has a time stamp on it. The time stamp describes the earliest model time at which the token can be moved by a binding element. Note here that one can define the time stamp unit as seconds, microseconds, or millennia and so on. It depends completely on the designer. Please note that the authors assume one time unit is equal to one second in this chapter and the definitions of TCPN are going to be presented here in a compact way and follow the original definitions of TCPN by [23-24].

Definition 1: A timed non-hierarchical CP-nets is a tuple TCPN $=\left(C P N, R, r_{0}\right)$ such that:

1. $\mathrm{CPN}=(\Sigma, \mathrm{P}, \mathrm{T}, \mathrm{A}, \mathrm{N}, \mathrm{C}, \mathrm{G}, \mathrm{E}, \mathrm{I})$ satisfying the requirements below:

(1) $\Sigma$ is a finite set of non empty types, called colour sets.

(2) $P$ is a finite set of places.

(3) $\mathrm{T}$ is a finite set of transitions.

(4) $\mathrm{A}$ is a finite set of arcs such that: $\mathrm{P} \cap \mathrm{T}=\mathrm{P} \cap \mathrm{A}=\mathrm{T} \cap \mathrm{A}=\varnothing$.

(5) $\mathrm{N}$ is a node function. It is defined from $\mathrm{A}$ into $\mathrm{P} \times \mathrm{T} \cup \mathrm{T} \times \mathrm{P}$. 
(6) $C$ is a colour function. It is defined from $P$ into $\Sigma$.

(7) $G$ is a guard function. It is defined from $T$ into expressions.

(8) $\mathrm{E}$ is an arc expression function. It is defined from $\mathrm{A}$ into expressions.

(9) I is an initialization function. It is defined from P into closed expressions that an expression is without variables.

2. $\mathrm{R}$ is a set of time values, also called time stamps. It is closed under + and containing 0 .

3. $\mathrm{r}_{0}$ is an element of $\mathrm{R}$ called the start time.

Definition 2: A binding of transition $t$ is a function $b$ defined on $\operatorname{Var}(t)$ which is called the set of variables of $\mathrm{t}$. $\mathrm{B}(\mathrm{t})$ is denoted the set of all binding for $\mathrm{t}$.

Definition 3: A binding element is a pair $(t, b)$ where $t \in T$ and $b \in B(t)$. The set of all binding elements is denoted by BE.

Definition 4: A step $\mathrm{Y}$ is enabled in a marking $\mathrm{M}$ iff the following properties are satisfied:

$$
\forall p \in P: \sum_{(t, b) \in Y} E(p, t)<b>\leq M(p)
$$

The expression evaluation $\mathrm{E}(\mathrm{p}, \mathrm{t})<\mathrm{b}>$ yields the multi-set of token colours, which are removed from $\mathrm{p}$ when $\mathrm{t}$ occurs with the binding $\mathrm{b}$. For a time concept, the enabled definition is modified as follows:

A step $\mathrm{Y}$ is enabled in a state $\left(\mathrm{M}_{1}, \mathrm{r}_{1}\right)$ at time $\mathrm{r}_{2}$ iff the following properties are satisfied:

1. $\forall p \in P: \sum_{(t, b) \in Y} E(p, t)<b>_{r_{2}} \leq M_{1}(p)$

2. $r_{1} \leq r_{2}$.

3. $\mathrm{r}_{2}$ is the smallest element of $\mathrm{R}$ for which there exists a step satisfying above two restrictions.

Next, the definition is relation with place invariant.

Definition 5: For a non-hierarchical CP-net, a set of place weights with range $A \in \Sigma$ is a set of functions $W=\left\{W_{p}\right\}_{p_{\in P}}$ such that $W_{P} \in\left[C(p)_{W S} \rightarrow A_{W S}\right]_{L}$ for all $p \in P$.

1. $\mathrm{W}$ is a place flow iff

$\forall(t, b) \in B E: \sum_{p \in P} W_{P}(E(p, t)<b>)=\sum_{p \in P} W_{P}(E(p, t)<b>)$.

2. W determines a place invariant iff:

$$
\forall M \in\left[M_{0}>: \sum_{p \in P} W_{P}(M(p))=\sum_{p \in P} W_{P}\left(M_{0}(p)\right) \cdot\right.
$$

Note that the invariant property in 2 is a dynamic property, while the flow property in 1 is a static property. It hints that the static property which can be checked without considering the set of all reachable markings.

\section{Modelling of traffic light systems by using TCPN}

One can see frequently the vehicle goes straight and turns right in an intersection with twoway roads. In this chapter, a traffic system with the two phases (i.e. shown in table I), called a basic traffic system, will be introduced in this section. The two phases consist of phase_NS and phase_EW. And the operations are described as follows. In phase_NS, the northbound and southbound vehicles are allowed to go straight and turn right. In phase_EW, the westbound and eastbound vehicles are allowed to go straight and turn right. 
Table 1. The two phase transitions.

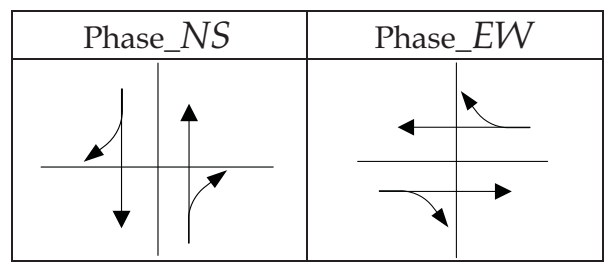

A schedule of the traffic signals is given in table II for this intersection. At first, the definitions of "period cycle" that represents one cycle of a period and "day cycle" that represents one cycle of a day are introduced. There are several periods in a day cycle and they represent the intervals which are continuous execution times. The duration of the phase_NS represents the time of the vehicles can go and pass the intersection in NS direction. Similarly, the duration of the phase_EW is the vehicle can pass through the intersection in EW direction. The duration of the two phases include both the duration of green and the duration of yellow. A cycle time is defined as the summation of the two durations. It is worthy to notice that there are with many repetition cycles in a period. For example, the numbers of repetition cycles are 30 in one hour if its cycle time is 120 seconds.

\begin{tabular}{|l|l|l|l|l|}
\hline Period & $\mathrm{t}_{1}$ & $\mathrm{t}_{2}$ & $\ldots$ & $\mathrm{t}_{i}$ \\
\hline Execution time & $0-\mathrm{h}_{1}$ & $\mathrm{~h}_{1}-\mathrm{h}_{2}$ & $\ldots$ & $\mathrm{h}_{i-1}-\mathrm{h}_{i}$ \\
\hline Phase_NS duration & $\mathrm{\tau}_{11}$ & $\mathrm{\tau}_{12}$ & $\ldots$ & $\mathrm{\tau}_{1 i}$ \\
\hline Phase_EW duration & $\mathrm{\tau}_{21}$ & $\mathrm{\tau}_{22}$ & $\ldots$ & $\mathrm{\tau}_{2 i}$ \\
\hline Cycle time & $\mathrm{ct}_{1}$ & $\mathrm{ct}_{2}$ & $\ldots$ & $\mathrm{ct}_{j}$ \\
\hline
\end{tabular}

Table 2. A schedule of traffic light signals.

Here, the chapter focuses on how to model the traffic lights using TCPN. It is an interesting work for the traffic light system model. It is worthy to notice that three TCPN models are constructed in Figure 1 by three type lines. 


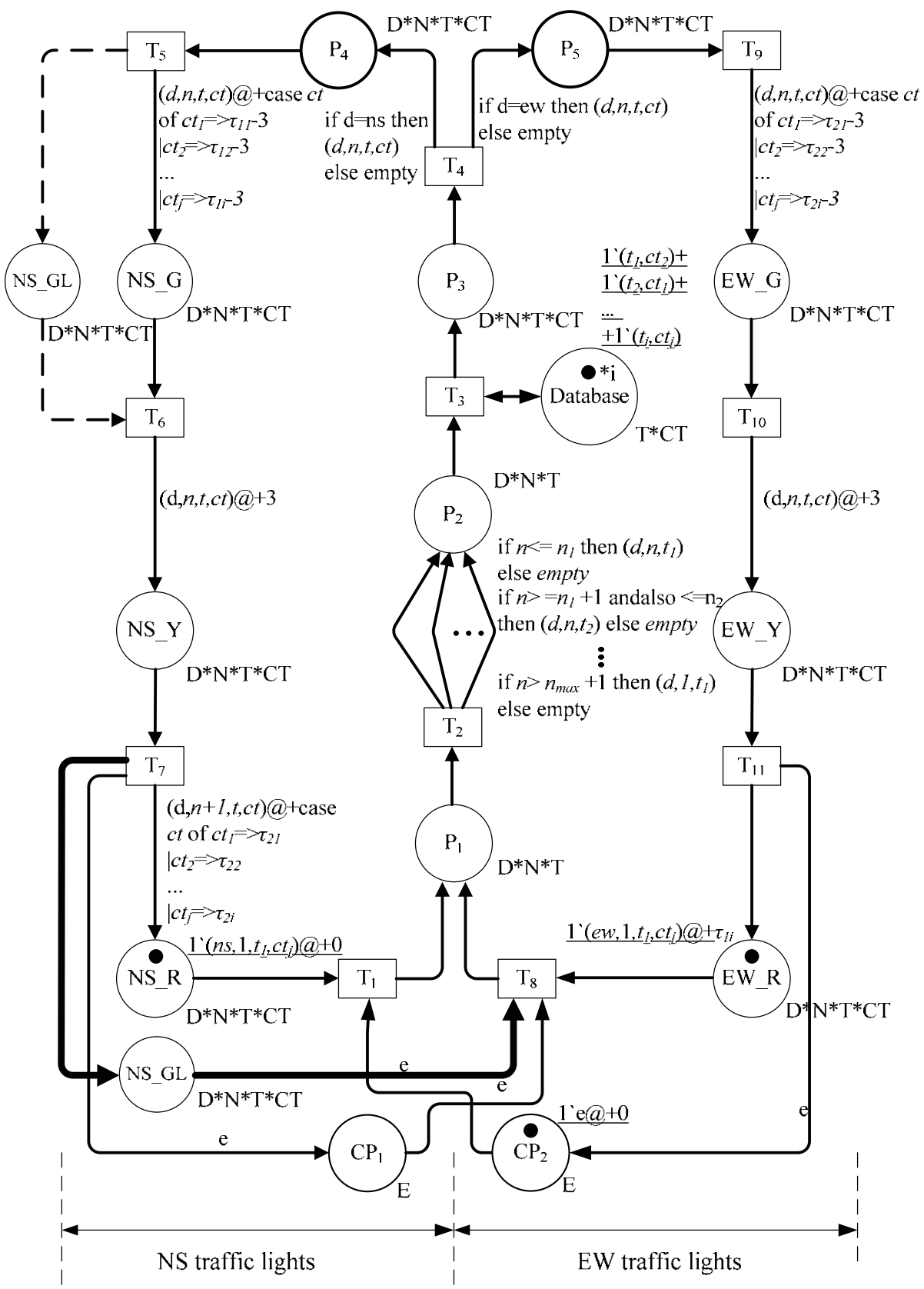

Fig. 1. An intersection TCPN model. 
One is the basic traffic system model whose is modeled by normal lines. The other one is an extended model which is added with dash lines. Another one is also an extended model which is added with heavy lines. The two type extended models will be explained later. The basic traffic system model consists of two main parts: the left part which is called the NS traffic lights describes the states of both the northern and southern traffic lights; the right part which is called the EW traffic lights depicts the states of both the eastern and western traffic lights. More precisely, each part can be divided into two sub-models. One submodel is for the signal indication and the other is for the signals' timing whose model is shared between the signal indication models. The duration of the yellow is assumed as 3 seconds and the lost time [11] are neglected in this chapter. The more detailed information is described as follows.

\subsection{Signal indication models}

Usually, the green light means the vehicles can go straight and turn right. And the vehicles do not permit turning left. In the pioneer works [17-20], this situation is hardly presented in detail. However, this case is easily modeled by the new methodology. A signal indication model can show the traffic light in red, yellow or green. The traffic lights are modeled as places EW_G, EW_Y, EW_R, NS_G, NS_Y, and NS_R (i.e. Figure 1). The places of the traffic lights are triggered by tokens in the TCPN model. Based on the rules of TCPN, the tokens are defined as 4-tuple $(\mathrm{d}, \mathrm{n}, \mathrm{t}, \mathrm{ct})$ with time stamp. The first element $\mathrm{d}$ represents the traffic lights in NS/EW. Thus it can be written as $d \in\{n s, e w\}$. The second one $n$ (i.e. $n \in I^{+}$) represents the numbers of the repetition cycles. The element $t$ stands for the period time, where $t \in \mathrm{I}^{+}$. The final element ct represents the cycle time, where ct $\in \mathrm{I}^{+}$. Here, $\mathrm{I}^{+}$is nonnegative integer.

Places NS_G, NS_Y, NS_R, EW_G, EW_Y, EW_R, CP 1 and $C_{2}$ belong to this sub-model. A token in place NS_G means the green lights turn on in NS traffic lights. And then place NS_Y (NS_R) with a token represents the yellow (red) lights turn on in NS traffic lights. Similarly, the places EW_G, EW_Y and EW_R with tokens means the green lights, yellow lights and red lights turn on in EW traffic lights, respectively. Places $\mathrm{CP}_{1}$ and $\mathrm{CP}_{2}$ play the guard roles, which guarantee only one direction is allowed to proceed for the vehicle streams. For example, when the green light turns on in NS, the red light turns on in EW. More specifically, the two places ensure the safety of the traffic. The transitions of the system model will be introduced in the following paragraph.

The transitions $\mathrm{T}_{5}$ and $\mathrm{T}_{9}$ stand for the green durations. Because the duration of the phase involves green duration and yellow duration (i.e. 3 seconds), the time inscription $\tau-3$ that deducts yellow duration from phase duration is a green duration. The transitions $\mathrm{T}_{6}$ and $\mathrm{T}_{10}$ represent the yellow duration (i.e. 3 seconds). The transition $\mathrm{T}_{7}$ stands for the red durations in NS. And then the red duration in EW is controlled by the token of place $\mathrm{CP}_{1}$. The physical means the red light of the traffic lights in EW is going on till the enabled binding element $\left(T_{8}, e\right)$ is taken. Obviously, the red duration of traffic lights in EW is the $\tau_{1 i}$ seconds. It reveals that the vehicle streams only proceed in either NS or EW.

Based on the basic sub-model, two types of extended signal indication models which involve a left turn arrow on green are obtained. The first one is added with the dashed lines in Figure 1 which describes the left turn arrow on green to be triggered with the right turn 
arrow on green and go straight arrow on green at the same time. In other words, the three green lights are turned on concurrently. In this extended signal indication model, the authors add a place NS_GL to the basic traffic model. And it represents the left turn green light. The second one is added with heavy lines in Figure 1 which indicates only one of the three green lights (left turn green light, go straight green light, and right turn green light) goes on. It means that the left turn green light (NS_GL) is going on after the other two green lights (NS_G) turn off. For this purpose, the authors add a place NS_GL to the basic model. It also represents the left turn green light. It is worthy to notice that the two types of extended signal indication models in Figures 1 just only describe one part of NS traffic lights. The attached places and transitions can also be constructed the part of EW traffic lights. The extended signal indication model is useful in the multi-phase transitions.

\subsection{Signal timing plan models}

The sub-model of the signal timing plan model is the kernel of the TCPN model (i.e. Figure 1). It is the model's duty to assign the cycle times to the different periods. Especially, there are no durations and delay times in the sub-model. Indeed, it is used to estimate what is the cycle time of a period. In the sub-model, one has to count the numbers (i.e. $\mathrm{n}_{i}$ ) of the repetition cycle. Once the number of repetition cycles meets the number $\mathrm{n}_{i}$, the current period $t_{i}$ will enter next period $t_{i+1}$. And then a new cycle time will be given in terms of period $\mathrm{t}_{i+1}$.

The definitions of the elements of tokens in the sub-model are the same as the signal indication model. It is worthy to notice that the component elements of token in this submodel consists of two (i.e. $(t, c t))$, three (i.e. $(d, n, t))$, or four (i.e. $(d, n, t, c t)$ ) elements. And the signal indication model consists of four elements (i.e. $(d, n, t, c t))$. The more explicit expression describing as follows.

There are several arc expressions between transition $\mathrm{T}_{2}$ and place $\mathrm{P}_{2}$. The arc expressions determine when the current period goes to next period. The repetition cycle time in a "period cycle" is represented by $\mathrm{r}_{i}$. And a values $\mathrm{n}_{i}$ is determined from the formula, where $n_{i}=\sum_{i=1}^{n} r_{i}, n \in I^{+}$. For example, $\mathrm{n}_{2}=\mathrm{r}_{1}+\mathrm{r}_{2}$. Once the number of repetition cycles is equal to $\mathrm{n}_{i}$. The current period $\left(\mathrm{t}_{i}\right)$ will go to the next period $\left(\mathrm{t}_{i+1}\right)$. And then the current token $(\mathrm{d}$, $\left.\mathrm{n}, \mathrm{t}_{i}\right)$ will change to $\left(\mathrm{d}, \mathrm{n}, \mathrm{t}_{i+1}\right)$. In addition, a maximum number of repetition cycles $\mathrm{n}_{\max }$ for the "day cycle" is required. Because the system model needs a mechanic to judge what is the day off. At the new day, the number $\mathrm{n}_{\max }$ is enforced to reset. It means the state is coming back to the initial state.

In summary, when a token is removed from $P_{1}$ to $P_{2}$, the token is with a $t_{i}$. Once the token is removed from $\mathrm{P}_{2}$ to $\mathrm{P}_{3}$, the token is now with a $\mathrm{ct}_{i}$. Note that the $\mathrm{ct}_{i}$ is offered by the Place Database. The function of Place Database is that the model can show both of the cycle time and the current period together. Therefore, we have to create a database of $\left(\mathrm{t}_{i}, \mathrm{ct}_{j}\right)$ by tokens in Database. Meanwhile, the output token is changed and it is with four elements like as (d, $\left.\mathrm{n}, \mathrm{t}_{i}, \mathrm{ct}_{i}\right)$. 


\section{Analysis of the urban traffic net model}

A traffic light control system model must have correct and readable features. For example, the controller should not lock up (deadlock) due to some unexpected combination of actions, should not allow conflicting movements to have right of way simultaneously, should be able to serve all signal phases and return to some initial state. A major strength of TCPN is the availability of methods for analyzing the properties of the model. Those properties of TCPN model reveal weather the model is reliable or not.

There are three methods to analyze a TCPN model: 1) invariant method; 2) occurrence graphs method; and 3) simulation method [23]. In this section the basic traffic light control system model is analyzed by the occurrence graphs method and invariant method. In addition, a real-world urban traffic net which consists of three intersections is used to verify the model by simulation.

\subsection{Invariant method}

The basic ideal behind place invariants creates equations that are satisfied in all reachable marking [24]. In TCPN nets, the sets of removed tokens are not fully determined by the binding elements. Based on the rules of TCPN, a transition can be fired if the global time is great than or equal to the time stamp. It hints that the system acts according to the time stamps of the binding elements. In fact, the system models require only the time stamps to be small enough, instead of requiring them to have some exact time values. This means that linearity of weight functions is insufficient to guarantee that each flow determines an invariant. However, our traffic light TCPN model is predetermining time. Therefore, it is certainly to use invariants in analysis of TCPN models. The basic model (i.e. Figure 1) is used to analyze the place invariance. Based on the definition 5, we can obtain several equations from Figure 1. And the performance of the system should be verified by the equations. The detailed information is given as follows.

$$
N S \_G+N S \_Y+N S \_R+P_{1}+P_{2}+P_{3}+P_{4}=1
$$

This invariant states that they can be only one token in any one of the places involved in (1). And it indicates that the firing sequence of the binding elements should be in order at NS traffic light. For example, the variations of traffic lights are red, green and yellow in turn. Note that places $\mathrm{P}_{1}, \mathrm{P}_{2}, \mathrm{P}_{3}$, and $\mathrm{P}_{4}$ are necessary control places. Similarly, the other invariant can be obtained, i.e., EW_G+EW_Y+EW_R+P $+\mathrm{P}_{1}+\mathrm{P}_{2}+\mathrm{P}_{3}+\mathrm{P}_{5}=1$. This invariant asserts that, at any given time, there are only one token in the right-hand side of the display indication modules.

$$
\mathrm{NS} \_\mathrm{G}+\mathrm{NS} \_\mathrm{Y}+\mathrm{NS} \_\mathrm{R}+\mathrm{P}_{1}+\mathrm{P}_{2}+\mathrm{P}_{3}+\mathrm{P}_{4}=\mathrm{EW} \_\mathrm{R} \text {, where } \mathrm{EW} \_\mathrm{R}=1
$$

This invariant depicts that if there is one token in place EW_R, then there must be a token in either place NS_G, NS_Y, NS_R, $P_{1}, P_{2}, P_{3}$ or $P_{4}$. It means that once a red signal goes on in the EW traffic lights, then a green, a yellow or a red signal turns on in the NS traffic lights.

In the other way, the invariant EW_G+EW_Y+EW_R+P $1+\mathrm{P}_{2}+\mathrm{P}_{3}+\mathrm{P}_{5}=\mathrm{NS} \_\mathrm{R}$ asserts that if there is one token in place NS_R, then there must be a token in either place EW_G, EW_Y, 
EW_R, $P_{1}, P_{2}, P_{3}$ or $P_{5}$. It shows that once a red signal is going on in the EW traffic lights, then a green, a yellow or a red turns on in the NS traffic lights.

$$
\mathrm{NS} \_\mathrm{G}+\mathrm{NS} \_\mathrm{Y}+\mathrm{EW} \_\mathrm{G}+\mathrm{EW} \mathrm{Y}_{-}+\mathrm{P}_{1}+\mathrm{P}_{2}+\mathrm{P}_{3}+\mathrm{P}_{4}+\mathrm{P}_{5}+\mathrm{CP}_{1}+\mathrm{CP}_{2}=1
$$

As mentioned above, this invariant means that the direction of the vehicles movement is either in NS or EW. This invariant hints that the system model guarantees the safety of traffic.

The three equations (1), (2), and (3) show the key invariants in the TCPN model. And the three key invariants show the system model is with invariant.

\subsection{Occurrence Graphs method}

The basic idea behind occurrence graphs (OG) is to construct a graph, which is shown in Figure 2), containing a node for each reachable marking and an arc for each occurring binding element. And also it is intuitive in this approach to see that there is no possibility of deadlock in the system model.

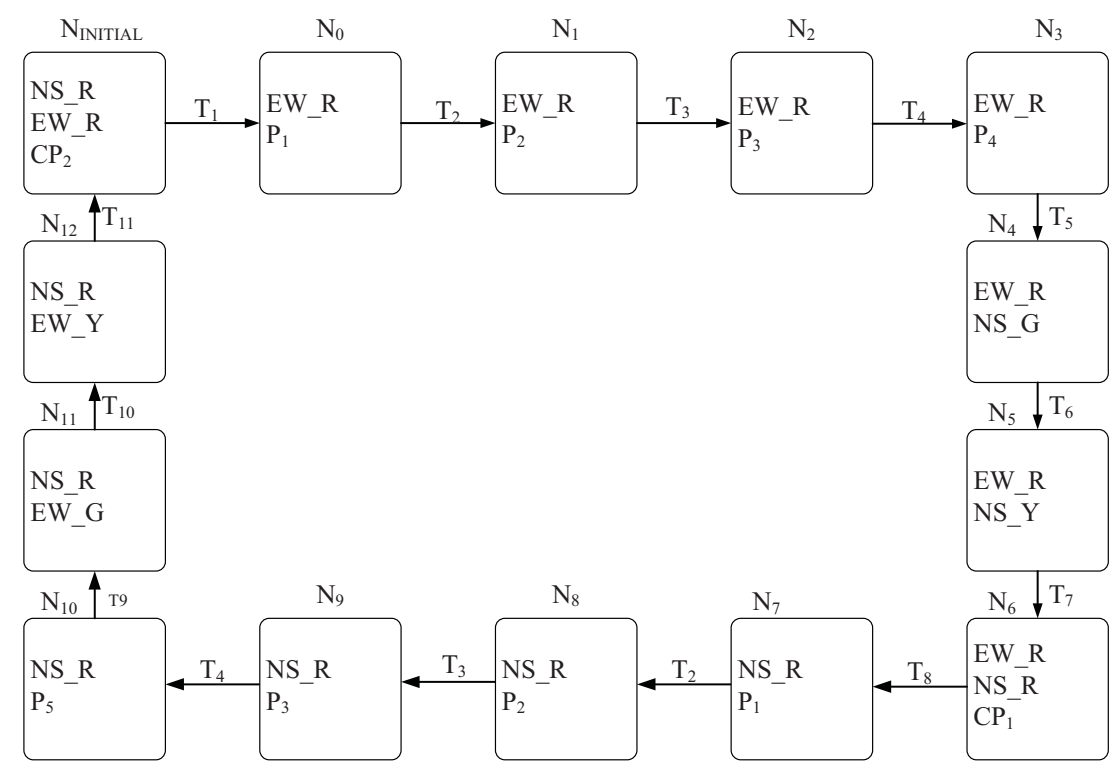

Fig. 2. The OG of the basic TCPN model.

It is worthy to notice that each node represents a marking, and the content of the marking is described by the text inscription of the node. And each arc represents the occurrence of a binding element, and the content of this binding element is described by the text attached to the arc. For example, the text EW_R and NS_G are used to describe the node $N_{5}$. This means that the red lights turn on in the EW traffic light. And the green lights turn on in the NS traffic lights. After a binding element $\mathrm{T}_{6}$ firing, the marking will be changed to node $\mathrm{N}_{6}$. It is worthy to notice that the initial marking (i.e., node $\mathrm{N}_{\text {INITIAL) }}$ shows all the red lights 
turn on in a set of traffic lights. For the sake of simplicity, the place Database is not shown in the OG.

Based on this analysis, it can be concluded that: 1) there are no dead-end nodes in the OG, therefore the net is live; 2) the net is reversible because we can always find an occurring sequence that bring the system back to the initial marking.

\subsection{The simulation results}

Considering the simulation, a real-world urban traffic net is used to verify the model. The real traffic net consists of five intersections which are shown in Figure 3. Some notations are employed to represent the five intersections. For example, 1NS_G means the green light goes on in the NS traffic light which is placed at intersection $\mathrm{I}_{1}$. Table 3 shows the information of the phase transitions in this real case. And also table 4 shows the signal time plan of traffic light model. The urban traffic net model will be constructed based on the basic traffic model. For convenience, the five intersections are divided into three types. One consists of intersection $\mathrm{I}_{1}, \mathrm{I}_{4}$ and $\mathrm{I}_{5}$ whose models are the same as the basic model. The other one is with intersection $\mathrm{I}_{2}$ whose model is obtained from the first extending model. Another one is with intersection $\mathrm{I}_{3}$ whose model is also from the second extending model. The detailed information of the urban net model is described as follows.

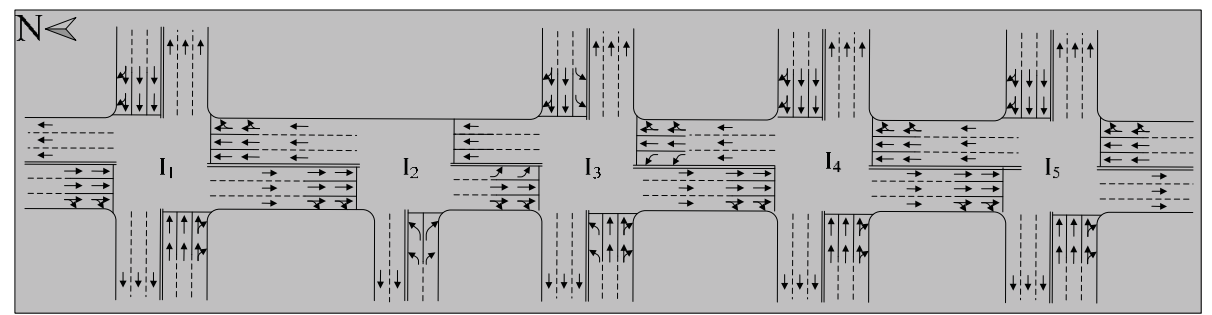

Fig. 3. A real-world urban traffic net.

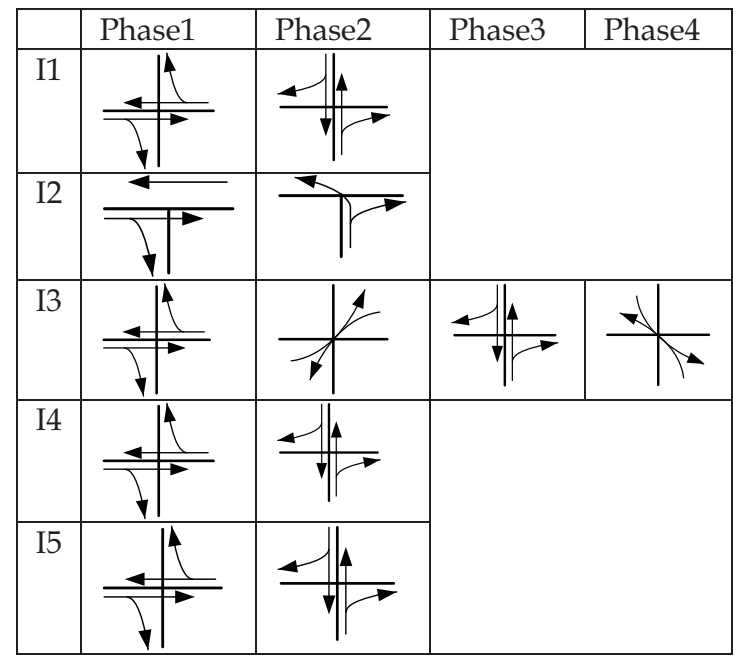

Table 3. The phase transitions of the traffic net. 


\begin{tabular}{|c|c|c|c|c|c|c|c|c|c|c|}
\hline & Period & $t_{1}$ & $t_{2}$ & $t_{3}$ & $\mathrm{t}_{4}$ & $t_{5}$ & $t_{6}$ & $t_{7}$ & $t_{8}$ & $t_{9}$ \\
\hline & $\begin{array}{l}\text { Executio } \\
\text { n time }\end{array}$ & $\begin{array}{c}00: 00 \\
- \\
01: 00\end{array} \mid$ & $\begin{array}{c}01: 00 \\
-05: 00\end{array}$ & $\begin{array}{c}05: 00 \\
-07: 00\end{array}$ & $\begin{array}{c}07: 00 \\
-09: 00\end{array}$ & $\begin{array}{l}09: 00 \\
-13: 00\end{array}$ & $\begin{array}{l}13: 00- \\
16: 30\end{array}$ & $\begin{array}{c}16: 30 \\
-19: 00\end{array}$ & $\begin{array}{r}19: 00 \\
-23: 00\end{array}$ & $\begin{array}{r}23: 00 \\
-24: 00\end{array}$ \\
\hline \multirow{3}{*}{ I1 } & Phase 1 & 60 & 46 & 60 & 110 & 110 & 110 & 110 & 95 & 60 \\
\hline & Phase 2 & 60 & 44 & 60 & 90 & 90 & 90 & 90 & 85 & 60 \\
\hline & $\begin{array}{l}\text { Cycle } \\
\text { time }\end{array}$ & 120 & 90 & 120 & 200 & 200 & 200 & 200 & 180 & 120 \\
\hline \multirow{3}{*}{ I2 } & Phase 1 & 80 & 60 & 80 & 140 & 140 & 140 & 140 & 120 & 80 \\
\hline & Phase 2 & 40 & 30 & 40 & 60 & 60 & 60 & 60 & 60 & 40 \\
\hline & $\begin{array}{l}\text { Cycle } \\
\text { time }\end{array}$ & 120 & 90 & 120 & 200 & 200 & 200 & 200 & 180 & 120 \\
\hline \multirow{5}{*}{ I3 } & Phase 1 & 55 & 30 & 55 & 85 & 85 & 85 & 85 & 80 & 55 \\
\hline & Phase 2 & 10 & 10 & 10 & 15 & 15 & 15 & 15 & 15 & 10 \\
\hline & Phase 3 & 45 & 40 & 45 & 85 & 85 & 85 & 85 & 70 & 45 \\
\hline & Phase 4 & 10 & 10 & 10 & 15 & 15 & 15 & 15 & 15 & 10 \\
\hline & $\begin{array}{l}\text { Cycle } \\
\text { time }\end{array}$ & 120 & 90 & 120 & 200 & 200 & 200 & 200 & 180 & 120 \\
\hline \multirow{3}{*}{ I4 } & Phase 1 & 60 & 45 & 60 & 100 & 100 & 100 & 100 & 90 & 60 \\
\hline & Phase 2 & 60 & 45 & 60 & 100 & 100 & 100 & 100 & 90 & 60 \\
\hline & $\begin{array}{l}\text { Cycle } \\
\text { time }\end{array}$ & 120 & 90 & 120 & 200 & 200 & 200 & 200 & 180 & 120 \\
\hline \multirow{3}{*}{ I5 } & Phase 1 & 90 & 60 & 90 & 160 & 160 & 160 & 160 & 140 & 90 \\
\hline & Phase 2 & 30 & 30 & 30 & 40 & 40 & 40 & 40 & 40 & 30 \\
\hline & $\begin{array}{l}\text { Cycle } \\
\text { time }\end{array}$ & 120 & 90 & 120 & 200 & 200 & 200 & 200 & 180 & 120 \\
\hline
\end{tabular}

Table 4 . The schedule of the signal timing plan.

\section{(1) Modeling of intersection $\mathrm{I}_{1}, \mathrm{I}_{4}$, and $\mathrm{I}_{5}$ (type I)}

The model of the type I is the same as basic traffic system's model. Hence, the module of basic traffic system could be applied directly to the type I. Form the schedule of the signal timing plan, there are four kinds of cycle time are given. For fitting the basic models, the notations $\mathrm{ct}_{1}=90, \mathrm{ct}_{2}=120, \mathrm{ct}_{3}=180$ and $\mathrm{ct}_{4}=200$ are assigned. And then the values of $\mathrm{r}_{i}$ and $\mathrm{n}_{i}$ have to be determined. The intersection $\mathrm{I}_{1}$ is used to illustrate how to obtain the values $r_{i}$ and $n_{i}$. Table 4 shows the execution time and the cycle time for every period of the intersection $\mathrm{I}_{1}$. From the table, the numbers of the repetition (i.e. $\mathrm{r}_{i}$ ) is easily to count. For example, the numbers of the repetition of $r_{1}$ is 30 for the period $t_{1}$ in the intersection $\mathrm{I}_{1}$. As a result, all the numbers of the repetition (i.e. $r_{i}$ ) are obtained and are shown in table 5 . Based on table 5 , the values $\mathrm{n}_{i}$ which is shown in table 6 is determined from the formula, where $n_{i}=\sum_{i=1}^{n} r_{i}, n \leq 9$. For example, $\mathrm{n}_{2}=\mathrm{r}_{1}+\mathrm{r}_{2}=30+160=190$. It is worthy to notice 
that the values of $r_{i}$ and $n_{i}$ in table 5 can be applied to intersections $I_{2}$ and $I_{3}$ since the three intersections have the same cycle time in a period.

Finally, three TCPN models of type I will be derived if the values $\mathrm{n}_{i}, \tau_{1 i}, \tau_{2 i}$, and $\mathrm{ct}_{j}$ are put into the original model (i.e. Figure 1). And then the three models (i.e. $\mathrm{I}_{1}, \mathrm{I}_{4}$ and $\mathrm{I}_{5}$ ) are given in Figure 4, 5 and 6, respectively.

\begin{tabular}{|l|l|l|l|l|l|l|l|l|l|}
\hline & $\mathrm{r}_{1}$ & $\mathrm{r}_{2}$ & $\mathrm{r}_{3}$ & $\mathrm{r}_{4}$ & $\mathrm{r}_{5}$ & $\mathrm{r}_{6}$ & $\mathrm{r}_{7}$ & $\mathrm{r}_{8}$ & $\mathrm{r}_{9}$ \\
\hline $\mathrm{r}_{\mathrm{i}}$ & 30 & 160 & 60 & 36 & 72 & 63 & 45 & 80 & 30 \\
\hline
\end{tabular}

Table 5. The values of $\mathbf{r}_{i}$.

\begin{tabular}{|l|l|l|l|l|l|l|l|l|l|}
\hline & $\mathrm{n}_{1}$ & $\mathrm{n}_{2}$ & $\mathrm{n}_{3}$ & $\mathrm{n}_{4}$ & $\mathrm{n}_{5}$ & $\mathrm{n}_{6}$ & $\mathrm{n}_{7}$ & $\mathrm{n}_{8}$ & $\mathrm{n}_{9}$ \\
\hline $\mathrm{n}_{\mathrm{i}}$ & 30 & 190 & 250 & 286 & 358 & 421 & 466 & 546 & 576 \\
\hline
\end{tabular}

Table 6. The values of $\mathrm{n}_{i}$. 


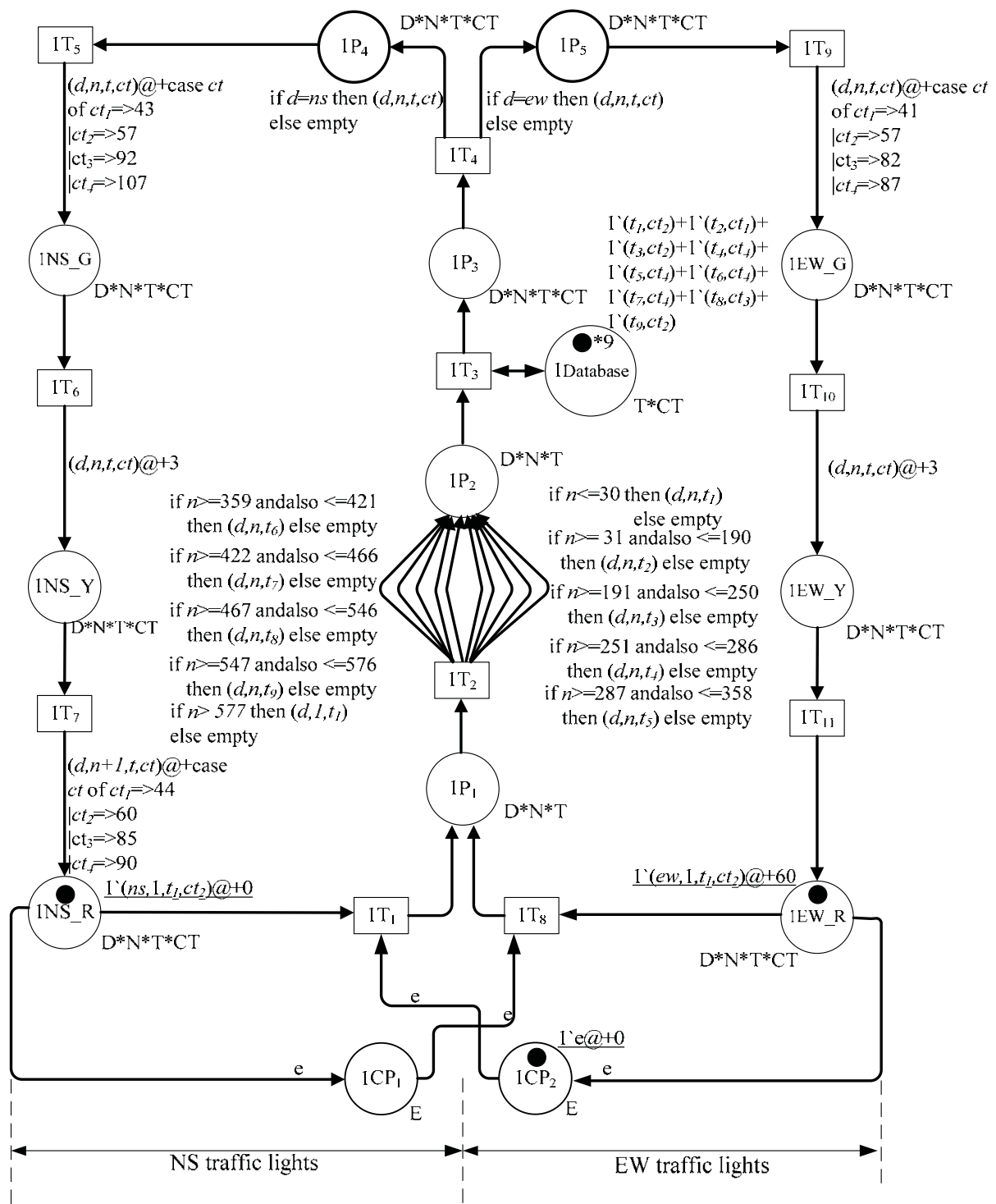

Fig. 4. The TCPN model of the intersection $\mathrm{I}_{1}$. 


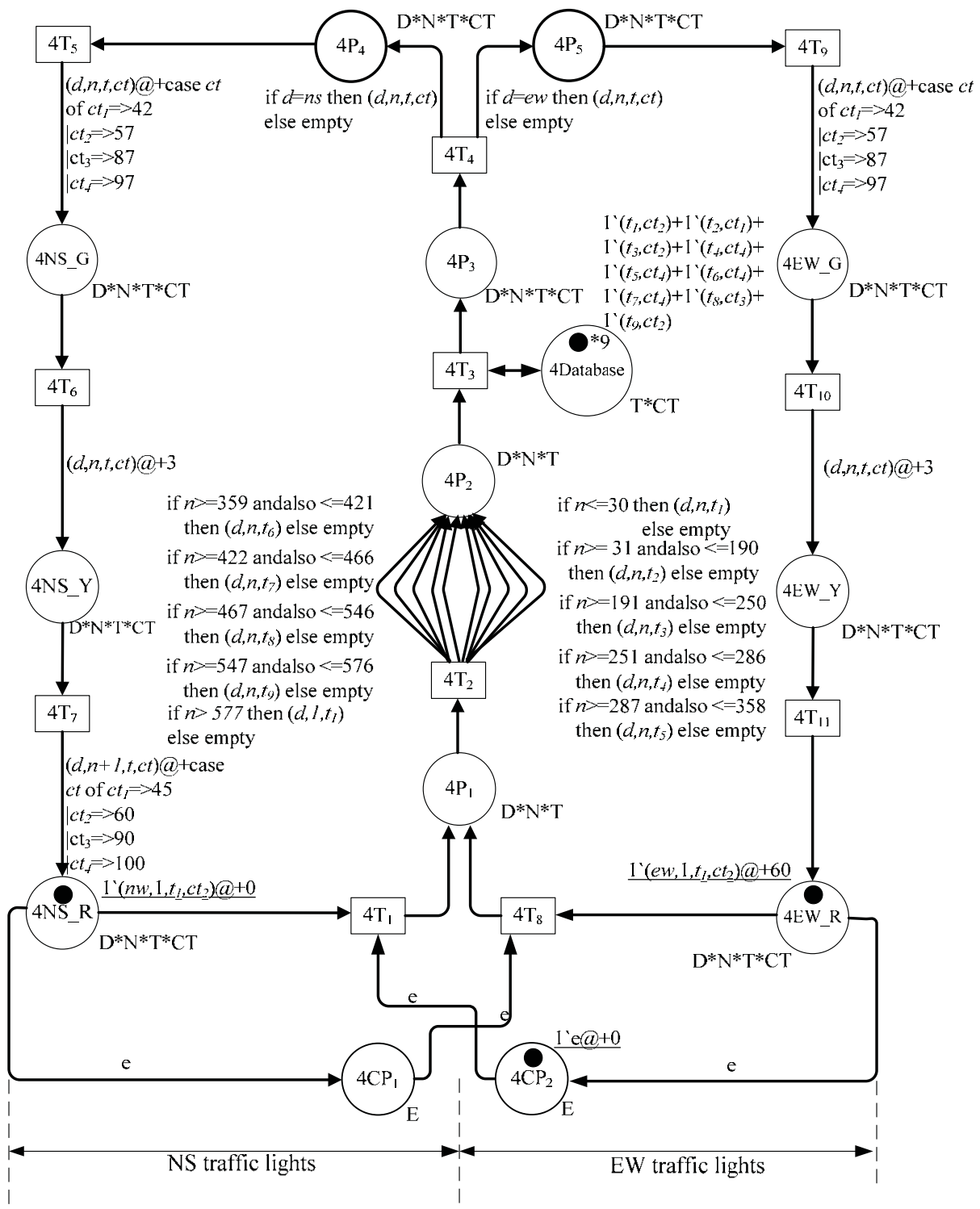

Fig. 5. The TCPN model of the intersection I4. 


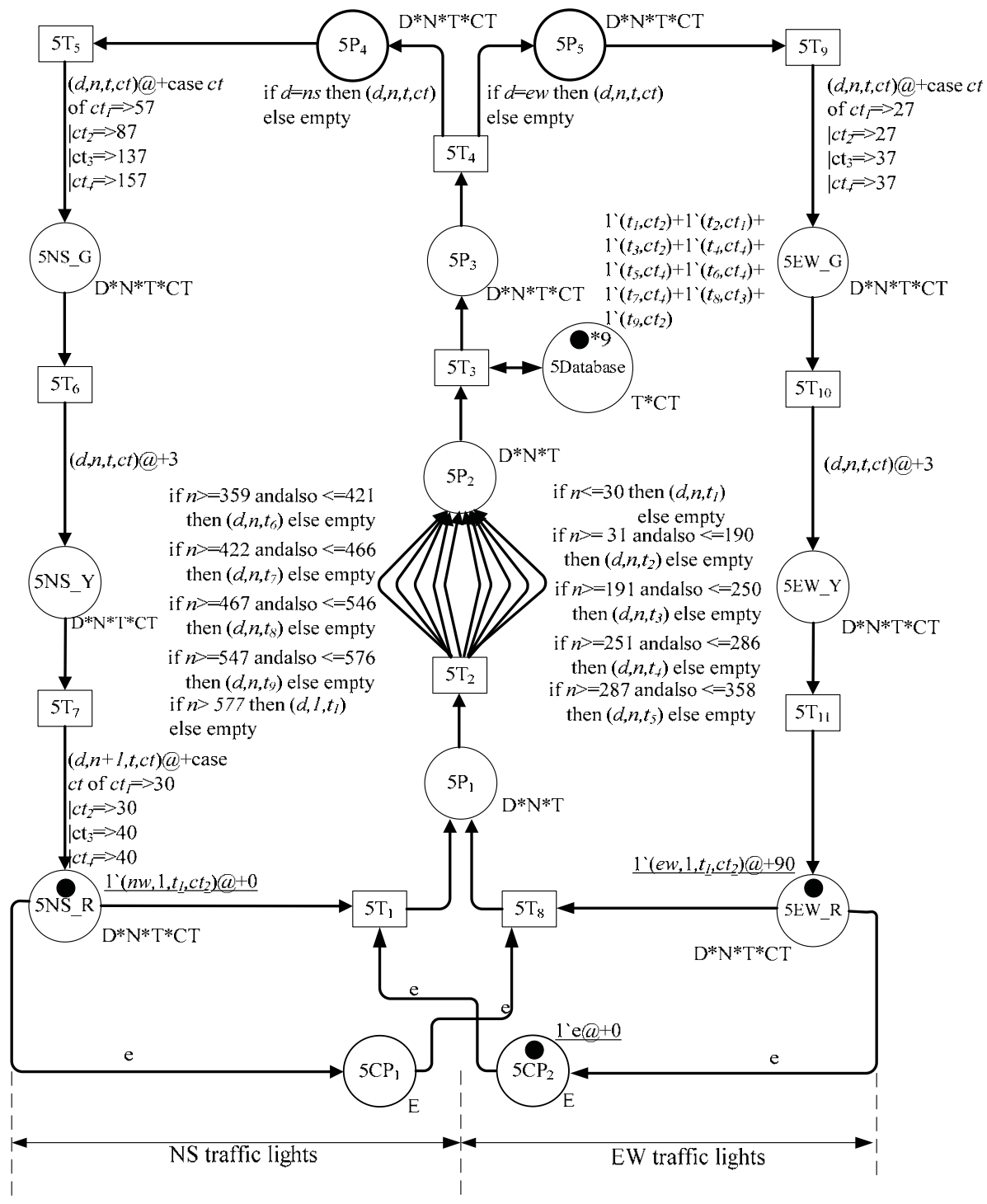

Fig. 6. The TCPN model of the intersection $\mathrm{I}_{5}$.

Based on the Place-invariant method, the three models should be verified by the following equations.

Intersection $\mathrm{I}_{1}$ :

$$
\begin{aligned}
& 1 \mathrm{NS}+G+1 \mathrm{NS} \text { Y }+1 \mathrm{NS} \_\mathrm{R}+1 \mathrm{P}_{1}+1 \mathrm{P}_{2}+1 \mathrm{P}_{3}+1 \mathrm{P}_{4}=1 \\
& 1 E W \_G+1 E W \_Y+1 E W \_R+1 P_{1}+1 P_{2}+1 P_{3}+1 P_{4}=1
\end{aligned}
$$




$$
\begin{aligned}
& \text { 1NS_G+1NS_Y+1NS_R+1P } 1+1 P_{2}+1 P_{3}+1 P_{4}=1 E W \text { R, where } 1 E W \_R=1 \\
& 1 \mathrm{EW} \text { G }+1 \mathrm{EW} \text {-Y+1EW_R+1P } 1+1 \mathrm{P}_{2}+1 \mathrm{P}_{3}+1 \mathrm{P}_{4}=1 \mathrm{NS} \_\mathrm{R} \text {, where } 1 \mathrm{NS} \_\mathrm{R}=1
\end{aligned}
$$

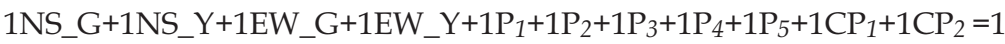

Intersection $\mathrm{I}_{4}$ :

$$
\begin{aligned}
& 4 \mathrm{NS} \_\mathrm{G}+4 \mathrm{NS} \text {-Y }+4 \mathrm{NS} \_\mathrm{R}+4 \mathrm{P}_{1}+4 \mathrm{P}_{2}+4 \mathrm{P}_{3}+4 \mathrm{P}_{4}=1 \\
& 4 \mathrm{EW} \text { G }+4 \mathrm{EW} \mathrm{Y}+4 \mathrm{EW} \_\mathrm{R}+4 \mathrm{P}_{1}+4 \mathrm{P}_{2}+4 \mathrm{P}_{3}+4 \mathrm{P}_{4}=1 \\
& 4 \mathrm{NS} \_\mathrm{G}+4 \mathrm{NS} \text { Y }+4 \mathrm{NS} \_\mathrm{R}+4 \mathrm{P}_{1}+4 \mathrm{P}_{2}+4 \mathrm{P}_{3}+4 \mathrm{P}_{4}=4 \mathrm{EW} \_\mathrm{R} \text {, where } 4 \mathrm{EW} \_\mathrm{R}=1 \\
& 4 \mathrm{EW} \_\mathrm{G}+4 \mathrm{EW} \_\mathrm{Y}+4 \mathrm{EW} \_\mathrm{R}+4 \mathrm{P}_{1}+4 \mathrm{P}_{2}+4 \mathrm{P}_{3}+4 \mathrm{P}_{4}=4 \mathrm{NS} \_\mathrm{R} \text {, where } 4 \mathrm{NS} \_\mathrm{R}=1 \\
& 4 \mathrm{NS} \_\mathrm{G}+4 \mathrm{NS} \text { YY+4EW_G+4EW_Y }+4 \mathrm{P}_{1}+4 \mathrm{P}_{2}+4 \mathrm{P}_{3}+4 \mathrm{P}_{4}+4 \mathrm{P}_{5}+4 \mathrm{CP}_{1}+4 \mathrm{CP}_{2}=1
\end{aligned}
$$

Intersection $\mathrm{I}_{5}$ :

$$
\begin{aligned}
& 5 \mathrm{NS} \_\mathrm{G}+5 \mathrm{NS} \_\mathrm{Y}+5 \mathrm{NS} \_\mathrm{R}+5 \mathrm{P}_{1}+5 \mathrm{P}_{2}+5 \mathrm{P}_{3}+5 \mathrm{P}_{4}=1 \\
& \text { 5EW_G+5EW_Y+5EW_R+5P }+5 \mathrm{P}_{2}+5 \mathrm{P}_{3}+5 \mathrm{P}_{4}=1 \\
& 5 \mathrm{NS} \_\mathrm{G}+5 \mathrm{NS} \_\mathrm{Y}+5 \mathrm{NS} \_\mathrm{R}+5 \mathrm{P}_{1}+5 \mathrm{P}_{2}+5 \mathrm{P}_{3}+5 \mathrm{P}_{4}=5 \mathrm{EW} \_\mathrm{R} \text {, where } 5 \mathrm{EW} \_\mathrm{R}=1 \\
& \text { 5EW_G+5EW_Y+5EW_R+5P } 1+5 \mathrm{P}_{2}+5 \mathrm{P}_{3}+5 \mathrm{P}_{4}=5 \mathrm{NS} \_\mathrm{R} \text {, where } 5 \mathrm{NS} \_\mathrm{R}=1 \\
& 5 \mathrm{NS} \_\mathrm{G}+5 \mathrm{NS} \_\mathrm{Y}+5 \mathrm{EW} \_\mathrm{G}+5 \mathrm{EW} \_\mathrm{Y}+5 \mathrm{P}_{1}+5 \mathrm{P}_{2}+5 \mathrm{P}_{3}+5 \mathrm{P}_{4}+5 \mathrm{P}_{5}+5 \mathrm{CP}_{1}+5 \mathrm{CP}_{2}=1
\end{aligned}
$$

(2) Modeling of intersection $\mathrm{I}_{2}$ (type II)

A T-type intersection is usually presented in a real-world urban traffic system. A feature of the T-type intersection is that one way of the vehicle stream can not be allowed to go straight. For this reason, a left turn arrow on green is needed to present in the traffic light system. As a result, the function of the left turn green light can be presented when a place NS_GL is added on the original model. It is interesting that the completed TCPN model of the T-type intersection (i.e. Figure 7) can be derived after a minor revision of the first extended traffic system model.

Form the definition of the phases (i.e. table 3), a right turn movement is absent in northern traffic light (i.e. phase 1 of $\mathrm{I}_{2}$ ). For convenience, i.e., in the extended model (i.e. Figure 7), the place NS_G is used to represent the vehicle stream can be allowed to go straight in the northbound traffic light and the other way can be allowed to go straight and turn right. In addition, the vehicle stream can not be allowed to go straight in the eastbound (i.e. phase 2 of $I_{2}$ ). This situation is different form the phase of the basic model (i.e. phase 2 of $\mathrm{I}_{1}$ ). By the same reason, the place E_G is used to represent the vehicle stream can be allowed to turn right and turn left in the eastern traffic light. Notice that the place EW_G/ EW_GL is instead by place E_G/E_GL in the new extended TCPN model.

Finally, the TCPN model of the T-type will be derived if the values $\mathrm{n}_{i}, \tau_{1 i}, \tau_{2 i}$, and $\mathrm{ct}_{j}$ are put into the original model. And then the model is constructed and is shown in Figure 7.

Based on the Place-invariant method, the model of intersection $\mathrm{I}_{2}$ should be verified by the following equations :

$$
\begin{gathered}
\text { 2NS_G+2NS_Y+2NS_R+ } 2 \mathrm{P}_{1}+2 \mathrm{P}_{2}+2 \mathrm{P}_{3}+2 \mathrm{P}_{4}=1 \\
2 \mathrm{~W} \_\mathrm{G}\left(2 \mathrm{~W} \_\mathrm{GL}\right)+2 \mathrm{~W} \_\mathrm{Y}+2 \mathrm{~W} \_\mathrm{R}+2 \mathrm{P}_{1}+2 \mathrm{P}_{2}+2 \mathrm{P}_{3}+2 \mathrm{P}_{4}=1
\end{gathered}
$$




$$
\begin{aligned}
& 2 \mathrm{NS} \_\mathrm{G}+2 \mathrm{NS} \_\mathrm{Y}+2 \mathrm{NS} \_\mathrm{R}+2 \mathrm{P}_{1}+2 \mathrm{P}_{2}+2 \mathrm{P}_{3}+2 \mathrm{P}_{4}=2 \mathrm{~W} \_\mathrm{R} \text {, where } 2 \mathrm{~W} \_\mathrm{R}=1 \\
& 2 \mathrm{~W} \_\mathrm{G}\left(2 \mathrm{~W} \_\mathrm{GL}\right)+2 \mathrm{~W} \_\mathrm{Y}+2 \mathrm{~W} \_\mathrm{R}+2 \mathrm{P}_{1}+2 \mathrm{P}_{2}+2 \mathrm{P}_{3}+2 \mathrm{P}_{4}=2 \mathrm{NS} \text { - } \mathrm{R} \text {, where } 2 \mathrm{NS} \_\mathrm{R}=1 \\
& 2 \mathrm{NS} \_\mathrm{G}+2 \mathrm{NS} \_\mathrm{Y}+2 \mathrm{~W} \_\mathrm{G}\left(2 \mathrm{~W} \_\mathrm{GL}\right)+2 \mathrm{~W} \_\mathrm{Y}+2 \mathrm{P}_{1}+2 \mathrm{P}_{2}+2 \mathrm{P}_{3}+2 \mathrm{P}_{4}+2 \mathrm{P}_{5}+2 \mathrm{CP}_{1}+2 \mathrm{CP}_{2}=1
\end{aligned}
$$

(3) Modeling of intersection $\mathrm{I}_{3}$ ( type III)

From the table 3, the phases of intersection $\mathrm{I}_{3}$ is with four phases. Obviously, one of the phases is with a left turn movement of intersection I3. The TCPN model of the intersection $\mathrm{I}_{3}$ can be easily obtained due to the phase is already included in the second extended model. As a result, the TCPN model of the intersection $\mathrm{I}_{3}$ can be constructed if the relations values are put into the original model. And the model is constructed and is shown in Figure 8.

Based on the Place-invariant method, the model of intersection $\mathrm{I}_{3}$ should be verified by the following equations :

$$
\begin{aligned}
& 3 \mathrm{NS} \_\mathrm{G}+3 \mathrm{NS} \text {-Y }+3 \mathrm{NS} \_\mathrm{R}+3 \mathrm{P}_{1}+3 \mathrm{P}_{2}+3 \mathrm{P}_{3}+3 \mathrm{P}_{4}=1 \\
& 3 \mathrm{EW} \_\mathrm{G}+3 \mathrm{EW} \_\mathrm{Y}+3 \mathrm{EWS} \_\mathrm{R}+3 \mathrm{P}_{1}+3 \mathrm{P}_{2}+3 \mathrm{P}_{3}+3 \mathrm{P}_{4}=1 \\
& 3 N S \_G+3 N S \_Y+3 N S \_R+3 P_{1}+3 P_{2}+3 P_{3}+3 P_{4}=3 E W \_R \text {, where } 3 E W \_R=1 \\
& 3 \mathrm{EW} \_\mathrm{G}+3 \mathrm{EW} \_\mathrm{Y}+3 \mathrm{EW} \_\mathrm{R}+3 \mathrm{P}_{1}+3 \mathrm{P}_{2}+3 \mathrm{P}_{3}+3 \mathrm{P}_{4}=3 \mathrm{NS} \_\mathrm{R} \text {, where } 3 \mathrm{NS} \_\mathrm{R}=1 \\
& 3 N S \_G+3 N S \_Y+3 N S \_G L+3 E W \_G+3 E W \_Y+3 E W \_G L+3 P_{1}+3 P_{2}+3 P_{3}+3 P_{4}+3 P_{5}+3 C P_{1} \\
& +3 \mathrm{CP}_{2}=1
\end{aligned}
$$

The TCPN models are implemented and simulated by the CPN tools [25]. Aim of the simulation is to observe the relation between cycle time and execution time in each period. Based on the schedule of the signal timing plan (i.e. table 4), the global time of the supervisor is set 86400 time units (i.e. one time unit is equal to one second) for the nine periods (i.e. $t_{1}, t_{2}, \ldots$, and $t_{9}$ ) in the CPN tools. In summary, the simulation results are the same as the predetermining time (i.e. table 4) and the cycle time of each period is consistent with table 4 . Moreover, the traffic performance can be confirmed by the simulation results. 


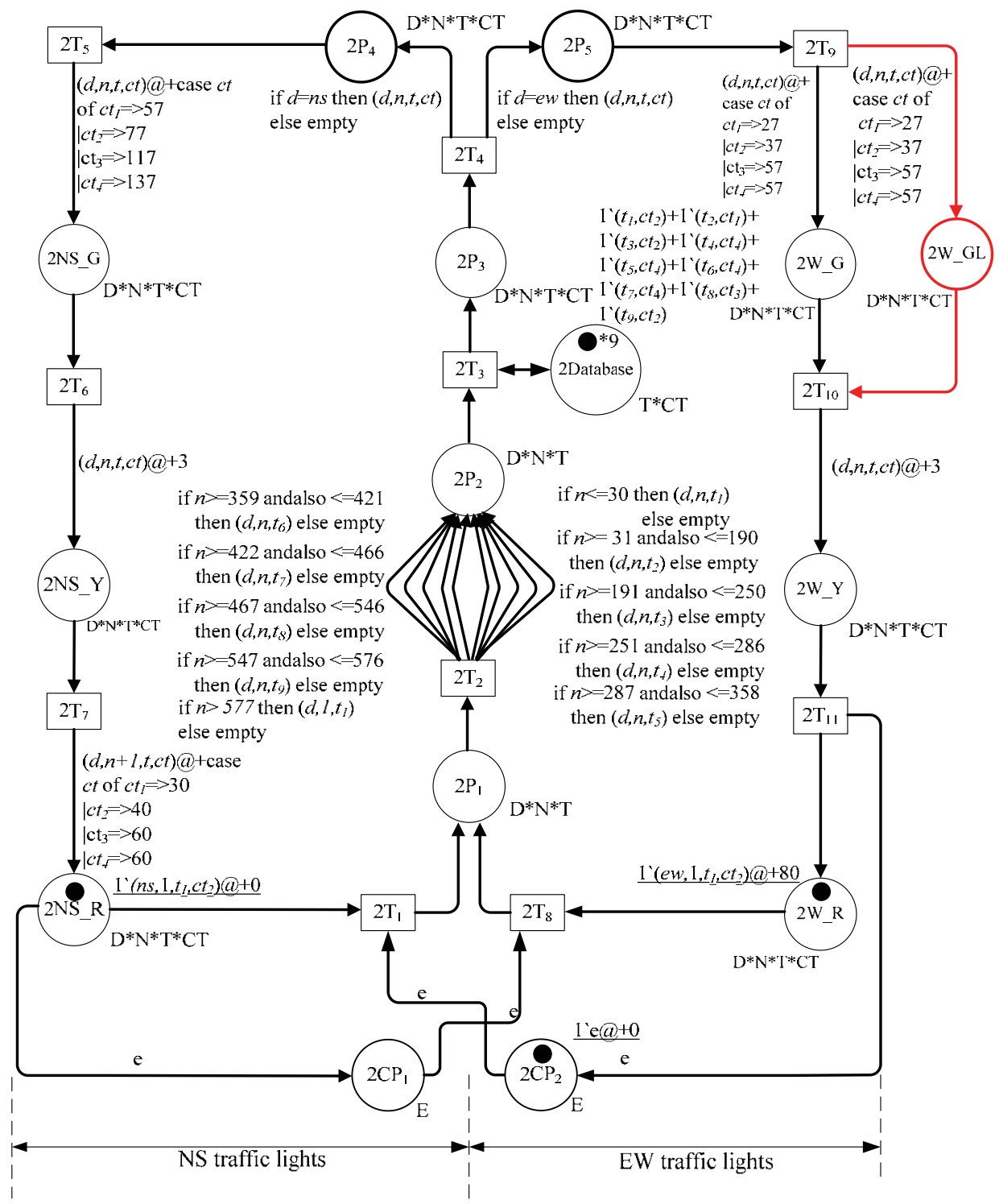

Fig. 7. The TCPN model of the intersection $\mathrm{I}_{2}$. 


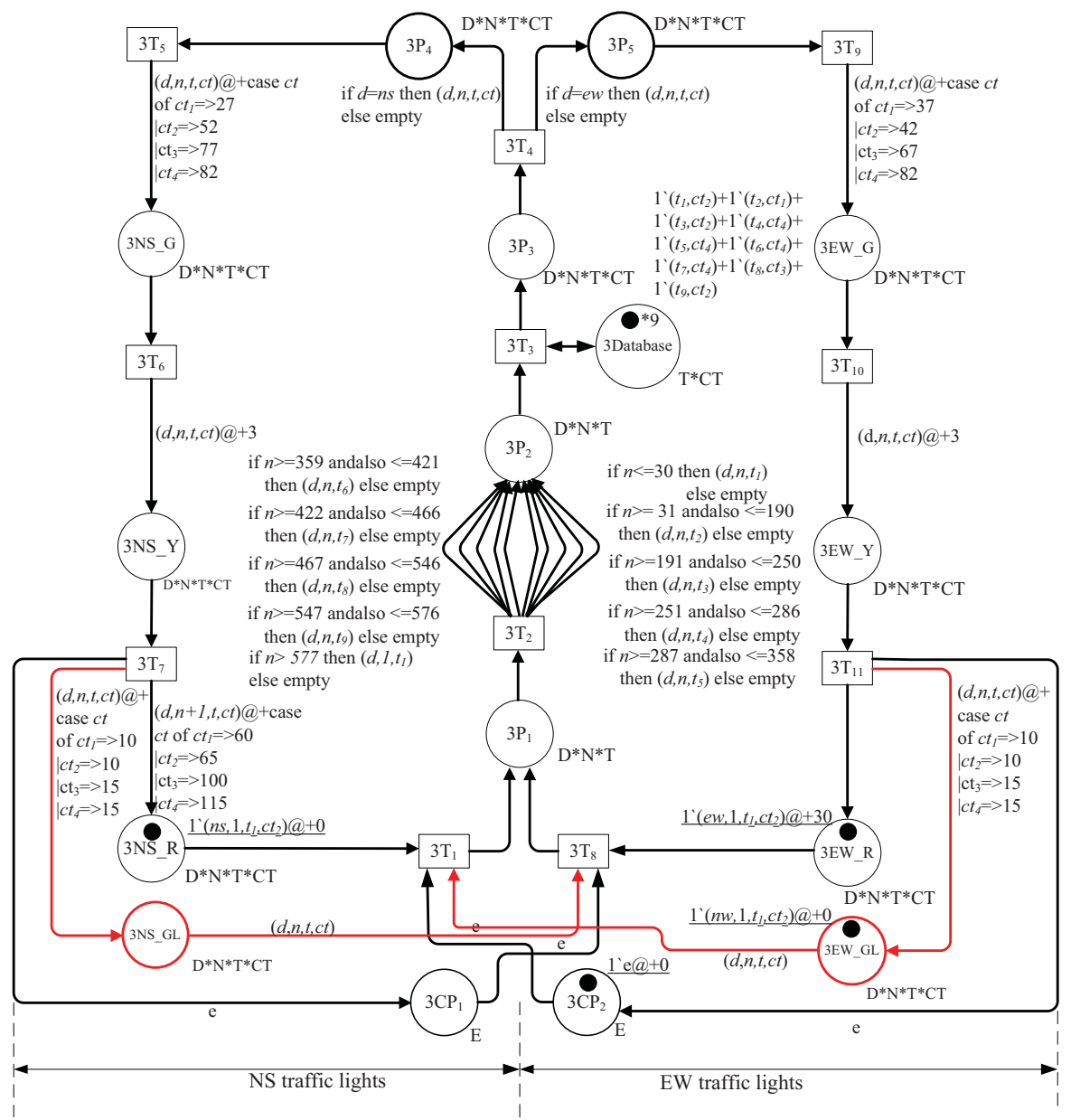

Fig. 8. The TCPN model of the intersection $\mathrm{I}_{3}$.

\section{Conclusion}

This chapter presents the modeling, analysis and implementation of an urban traffic lights system using TCPN models. Especially, this chapter also proposed the module of basic traffic light system model which can assist in designing the extended models. Based on the operational flow of the traffic lights systems, the authors derive the associated TCPN model by looking into the schedule of the signal timing plan of the traffic systems. The advantage of the proposed approach is the clear presentation of the system behavior and readiness for implementation. To summarize, this chapter has the following contributions.

This chapter has demonstrated how to use TCPN to model the traffic lights of the urban network. And then the applications of TCPN to urban traffic lights have been realized. Structural analysis of TCPN models was performed. 
The traffic systems with signal timing plan for a day is successful to convert TCPN models. These examples are helpful to us to obtain a TCPN model for a complex urban traffic lights system.

The authors believe that using TCPN to model traffic light systems will become more important in this field due to the increasing demands in many features of the traffic light systems.

\section{Acknowledgements}

This work was supported by the National Science Council of Taiwan, R.O.C. under Grant NSC 96-2221-E-606-029.

\section{References}

[1]Allsop, R. E.: 'SIGSET: A computer program for calculating traffic capacity of signalcontrolled road junctions', Traffic Eng. Control, 1971, 12, pp. 58-60.

[2]Allsop, R. E.: 'SIGCAP: A computer program for assessing the traffic capacity of signalcontrolled road junctions', Traffic Eng. Control, 1976, 17, pp. 338-341.

[3]Little, J. D. C.: 'The synchronization of traffic signals by mixed integer-linearprogramming', Oper. Res., 1966, 14, pp. 568-594.

[4]Little, J. D. C., Kelson, M. D., and Gartner, N. H.: 'MAXBAND: A Program for Setting Signals on Arteries and Triangular Networks', Transp. Res. Record, 1981, 795, pp. 40-46.

[5]Li, M. T., and Gan, A. C.: 'Signal timing optimization for oversaturated networks using TRANSYT-7F', Transp. Res. Record, 1999, 1683, pp. 118-126.

[6]Robertson, D.I.: 'TRANSYT method for area traffic control', Traffic Eng. Control, 1969, 10, pp. 276-281.

[7]Hunt, P. B., Robertson, D. L., and Bretherton, R. D.: 'The SCOOT on-line traffic signal optimization technique' Traffic Eng. Control, 1982, 23, pp. 190-192.

[8]Gartner, N. H.: 'OPAC: A demand-responsive strategy for traffic signal control', Transp. Res. Record, 1983, 906, pp. 75-81.

[9]Lim, J. H., Hwang, S. H., Suh, I. H. and Bien, Z.: 'Hierarchical optimal control of oversaturated urban traffic networks', International Journal of Control, 1981, 33, pp. 727-737.

[10]Davison, E. J., Ozguner U.: 'Decentralized control of traffic networks', IEEE Trans. Automat. Contr., 1983, 28, pp. 677-688.

[11]Papageorgiou M., Diakaki, C., Dinopoulou, V., Kotsialos, A., Wang, Y.: 'Review of Road Traffic Control Strategies', Proc. IEEE, Dec. 2003, pp. 2043-2067.

[12]List G. F., and Cetin M.: 'Modeling traffic signal control using Petri nets', IEEE Trans. on Intelligent Transportation Systems, 2004, 5, pp. 177- 187.

[13]Murata T.: 'Petri Nets: Properties, Analysis and Applications', Proc. IEEE, April, 1989, pp. 541-580, IEEE.

[14]Peterson J. L.: 'Petri net theory and the modeling of systems' (Prentice Hall, 1981)

[15]Febbraro A. D., Giglio D. and Sacco N.: 'Urban Traffic Control Structure Based on Hybrid Petri Nets', IEEE Trans. on Intelligent Transportation Systems, 2004, 5, pp. 224-237. 
[16]Tolba C., Thomas P., ElMoudni, A., and Lefebvre, D.: 'Performances evaluation of the traffic control in a single crossroad by Petri nets', Proceedings of IEEE Emerging Technologies and Factory Automation, Lisbon, Portugal, Sep. 2003, pp. 157-160.

[17]Tzes, A., Seongho, K., and McShane, W. R.: 'Application of Petri Networks to Transportation Network Modeling', IEEE Transactions on Vehicular Technology, 1996, 45, pp. 391-400.

[18]Wang, J., Jin, C. and Deng, Y.: 'Performance analysis of traffic networks based on stochastic timed Petri net models', Proceedings of IEEE Engineering of Complex Computer Systems, Las Vegas, NE, U.S., Oct. 1999, pp.77-85.

[19]Wang, H., List, G.F., and DiCesare, F.: 'Modeling and evaluation of traffic signal control using timed Petri nets', Proceedings of IEEE Systems, Man and Cybernetics, Le Touquet, France, 1993, pp. 180-185.

[20]Lin, L., Nan, T., Xiangyang, M. and Fubing, S.: 'Implementation of Traffic Lights Control Based on Petri Nets', Proceedings of IEEE Intelligent Transportation Systems, Shanghai, China, 2003, pp.1087-1090.

[21]Dotoli, M., Fanti, M.P. and Lacobellis, G.: 'Validation of an Urban Traffic Network Model using Colored Timed Petri nets', IEEE Int. Conf. on. Systems, Man and Cybernetics, Waikoloa, HI, U.S., 2005, pp. 1347-1352.

[22]Huang, Y. S.: 'Design of Traffic Light Control System Using Statecharts', Comp. J., 2006, 49, 634-649.

[23]Jensen K.: Coloured Petri Nets. vol. 1 (Springer-Verlag, 1997)

[24]Jensen K.: Coloured Petri Nets. vol. 2 (Springer-Verlag, 1995)

[25] http://wiki.daimi.au.dk/cpntools/cpntools.wiki, Computer Tool for Coloured Petri Nets. 


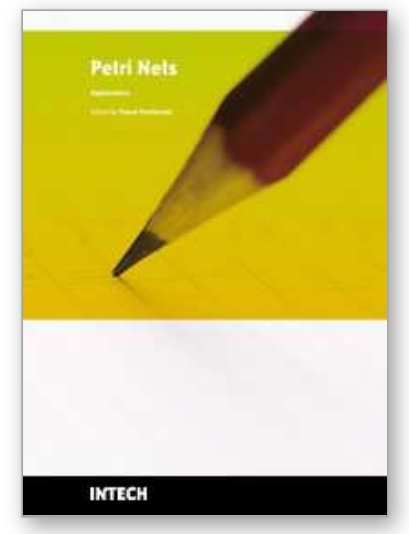

\author{
Petri Nets Applications \\ Edited by Pawel Pawlewski
}

ISBN 978-953-307-047-6

Hard cover, 752 pages

Publisher InTech

Published online 01, February, 2010

Published in print edition February, 2010

Petri Nets are graphical and mathematical tool used in many different science domains. Their characteristic features are the intuitive graphical modeling language and advanced formal analysis method. The concurrence of performed actions is the natural phenomenon due to which Petri Nets are perceived as mathematical tool for modeling concurrent systems. The nets whose model was extended with the time model can be applied in modeling real-time systems. Petri Nets were introduced in the doctoral dissertation by K.A. Petri, titled “"Kommunikation mit Automaten” and published in 1962 by University of Bonn. During more than 40 years of development of this theory, many different classes were formed and the scope of applications was extended. Depending on particular needs, the net definition was changed and adjusted to the considered problem. The unusual "flexibility" of this theory makes it possible to introduce all these modifications. Owing to varied currently known net classes, it is relatively easy to find a proper class for the specific application. The present monograph shows the whole spectrum of Petri Nets applications, from classic applications (to which the theory is specially dedicated) like computer science and control systems, through fault diagnosis, manufacturing, power systems, traffic systems, transport and down to Web applications. At the same time, the publication describes the diversity of investigations performed with use of Petri Nets in science centers all over the world.

\title{
How to reference
}

In order to correctly reference this scholarly work, feel free to copy and paste the following:

Yi-Sheng Huang and Ta-Hsiang Chung (2010). Modelling and Analysis of Traffic Light Control Systems Using Timed Coloured Petri nets, Petri Nets Applications, Pawel Pawlewski (Ed.), ISBN: 978-953-307-047-6, InTech, Available from: http://www.intechopen.com/books/petri-nets-applications/modelling-and-analysis-of-traffic-lightcontrol-systems-using-timed-coloured-petri-nets

\section{INTECH}

open science | open minds

\section{InTech Europe}

University Campus STeP Ri

Slavka Krautzeka 83/A

51000 Rijeka, Croatia

Phone: +385 (51) 770447

Fax: +385 (51) 686166

www.intechopen.com

\section{InTech China}

Unit 405, Office Block, Hotel Equatorial Shanghai

No.65, Yan An Road (West), Shanghai, 200040, China 中国上海市延安西路65号上海国际贵都大饭店办公楼405单元

Phone: +86-21-62489820

Fax: +86-21-62489821 
(C) 2010 The Author(s). Licensee IntechOpen. This chapter is distributed under the terms of the Creative Commons Attribution-NonCommercial-ShareAlike-3.0 License, which permits use, distribution and reproduction for non-commercial purposes, provided the original is properly cited and derivative works building on this content are distributed under the same license. 